\title{
Investigation of physical and chemical characteristics on soil due to crude oil contamination and its remediation
}

\author{
C. P. Devatha ${ }^{1} \cdot$ A. Vishnu Vishal ${ }^{1} \cdot$ J. Purna Chandra Rao ${ }^{1}$
}

Received: 14 June 2018 / Accepted: 5 May 2019 / Published online: 13 May 2019

(c) The Author(s) 2019

\begin{abstract}
Oil contamination causes serious geoenvironmental concern and adversely affects the soil environment due to the release of toxic by-products. Hence, the aim of the study was to investigate the influence of oil contamination on soil physical and chemical properties and phytoremediation as a treatment option based on field studies conducted for analyzing significant parameters. The sites selected were near National Institute of Technology, Surathkal, Karnataka (site-1), and another is close to the oil refinery (Kuthethur, Karnataka, India, as site-2). Phytoremediation of oil-contaminated samples was carried out by Chromolaena odorata. The evaluation of soil physical and chemical properties includes field and laboratory tests. A pumping test was conducted to estimate aquifer parameters in the field. The hydraulic conductivity for field soil sample (unsaturated condition) is carried out by a filter paper test. Laboratory tests to evaluate physical and chemical parameters include total petroleum hydrocarbons of contaminated (crude oil varying from 0 to $10 \%$ at an interval of $2 \%$ ) and uncontaminated samples and plant parameters. Characterization of contaminated and uncontaminated soil sample was performed by Fourier transform infrared (FTIR) spectroscopy. The results obtained reveal that physical properties of soil (moisture content, liquid and plastic limit) got affected due to oil contamination. Relative hydraulic conductivity was established as 0.46 (uncontaminated) and 0.57 (contaminated) for soil samples and led to the conclusion that hydraulic conductivity was drop down by $10 \%$ due to oil contamination. Total petroleum hydrocarbon analysis reveals that the uptake/presence of hydrocarbons by showing increased concentration in contaminated soils (5\% and 10\%) by the plant species. This is further confirmed by FTIR results. The TPH concentrations in the contaminated soils were reduced up to 50-60\% and also showed better plant growth after 7 weeks of transplantation. Hence, considered plant species possess high potential for degrading oil contaminated in the soil.
\end{abstract}

Keywords Soil properties $\cdot$ Hydraulic conductivity $\cdot$ Oil contamination $\cdot$ Phytoremediation $\cdot$ Petroleum hydrocarbons

\section{Introduction}

Environmental awareness is a widespread concern in achieving sustainable resources due to manmade interventions. Soil contamination due to petroleum products is of prime concern because it destroys the soil structure, biodegradability and results in serious health hazards when it gets exposed to the environment (Kathi and Khan 2011). The

$\triangle$ C. P. Devatha

revacp@gmail.com

A. Vishnu Vishal

a.vishnuvishal@gmail.com

J. Purna Chandra Rao

purnachandu92@gmail.com

1 Department of Civil Engineering, National Institute of Technology-Karnataka, Surathkal, India contamination of soil results in a change in soil properties, viz. soil moisture levels, hydraulic conductivity, Atterberg limits, total organic carbon, total nitrogen, available phosphorus, etc. Soil hydraulic properties play a pivotal role in estimating the water availability status of the aquifer. The measurement of soil suction is a decisive factor to arrive at the behavior of unsaturated soils. Soil suction is defined as the energy required for extracting unit volume of water from soil (Fredlund and Rahardjo 1993). The suction present in the unsaturated soil makes its behavior highly transient (varies with time) as compared to the steady-state behavior of saturated soils. Measuring soil suction in unsaturated soil is a critical process for the field samples. Filter paper technique is a simple and well-accepted method for measuring soil suction (Marinho and Oliveira 2006; Al-Khafaf and Hanks 1974; Hamblin 1981). 
The increasing contamination of soil is common and of great concern to our society and environment by various means viz. petroleum hydrocarbons, heavy metals, herbicides, pesticides and chlorinated hydrocarbons. Oil contamination is one of the severe problems because it comprises of contaminants like heavy metals and aromatic hydrocarbons. It makes the environment by overwhelming the soil particles which in turn blocks air diffusion in the pores of it (Sutton et al. 2013). Then, it results in a change of physical properties like Atterberg limits, permeability characteristics (Akunwumi et al. 2014; Nazir 2011; Al-Sanad et al. 1995) and chemical properties like $\mathrm{pH}$, total organic carbon, soil minerals nutrients such as sodium, potassium, sulfate, phosphate and nitrate of soil, thus indirectly affecting the growth and development of plants and microorganisms (Wang et al. 2010; Yalin et al. 2006; Ekundayo and Obuekwe 2000; Akubugwo et al. 2009). Hence, it becomes continuously detrimental and finally, its consequences lead to deprived crop growth and soil conditions.

Hence to encompass such situation, remediation of contaminated soil by the suitable technique is to be implemented. Phytoremediation is a cost-effective, plant-based natural approach for remediating the contaminated soil. Diesel contaminated soil by applying the plant species (Pinus densiflora, Populus tomentiglandulosa and Thuja orientalis) to achieve the degradation and further presented that the biomass production in the shoot can be used as a substrate for further analysis (Jagtap et al. 2014). Phytoremediation technique was investigated to degrade total petroleum hydrocarbons (TPH) (87\% in 90 days) in mangrove sediments and proved to be very effective by Rhizophora mangle leaves (Moreira et al. 2011). Degradation of the radioisotope of cesium by Chromolaena odorata was reported and $79 \%$ activity reduction in 15 days period was observed (Singh et al. 2009). Hence, developing practical applications will require a significant effort, due to the complexity of both biological systems and the soil contamination problems including a selection of plant species, plant uptake mechanisms, different pollutants and soil matrices without overseeing the microbial involvement.

Hence, in the present study, it is aimed to investigate soil characteristics (physical and chemical) for contaminated (crude oil) and uncontaminated soil condition. For contaminated soil, remediation was investigated by adopting phytoremediation. The present study is carried out in the following sequence. 1. Experimental investigation of soil geotechnical properties of contaminated and uncontaminated samples. To estimate the soil saturated and unsaturated hydraulic conductivity by the pumping test and filter paper test, respectively. 2. Cleanup method for soil contamination due to oil has been studied based on two significant directions, i.e., variation in soil properties and removal of hydrocarbons in the selected plant species. As per plant selection criteria (Kogbara 2007; Paz-Alberto and Sigua 2013), Chromolaena odorata (potential weed) is opted to perform phytoremediation. It grows rapidly and widely spread all around the Mangalore region, India, almost in all the seasons.

\section{Experimental work}

\section{Collection of soil sample}

The soil samples used in the study were collected from two sites. The sites are selected such as to investigate the properties of soil near to the beach and industrial area. The first sample was collected from NITK (site-1) campus. Hydraulic conductivity is one of the significant parameters that vary significantly with soil type. Hence, it is selected as one of the sites for investigation. Also, region, where we experimented, is a coastal region. The second sample from Kuthethur (site-2) area is of latitude $12^{\circ} 59^{\prime} 45.9^{\prime \prime} \mathrm{N}$ and longitude $74^{\circ} 50^{\prime} 29.2^{\prime \prime} \mathrm{E}$ nearer to the industrial area (petroleum industry).

After collecting the soil samples (between 40 and $50 \mathrm{~cm}$ below the ground surface), they were immediately brought to the laboratory for further analysis. Experiments were planned for the field samples and artificially contaminated samples (by adding crude oil of 5\% and 10\%) to identify and compare the behavior of soil properties.

Since Chromolaena odorata is a weed, manure was not added. After testing the initial characteristics of the soil, six pots of the same volume (7" diameter and $10^{\prime \prime}$ height) were taken and filled with the contaminated and blank soils as shown in Fig. 1a. Pots with 0\%, 5\% and 10\% crude oilcontaminated soil were prepared for both site soil samples for further experimentation. A disk of filter paper was placed in the bottom of each pot to prevent the soil from escaping out from the holes provided for proper drainage. To each pot, the plant was transplanted and left for stabilization in the contaminated environment (Fig. 1b). Soil when freshly contaminated was tested during the first week and after proper stabilization. Regular watering of plants was done. Soil samples collected (top and bottom) from each pot were subjected to the experimental investigation to TPH content in the soil.

\section{Soil characterization}

\section{Soil physical and chemical characterization}

Soil samples collected from the different sites were analyzed for its physical and chemical characteristics by adopting standard procedures and depicted in Table 1. 
Fig. 1 a Soil after contamination and filled in their corresponding pots, b after transplanting Chromolaena odorata in corresponding contaminated soil (a)

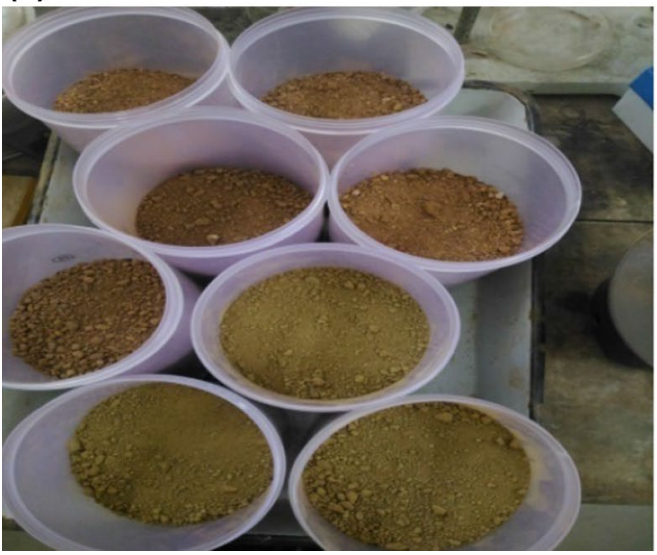

(b)

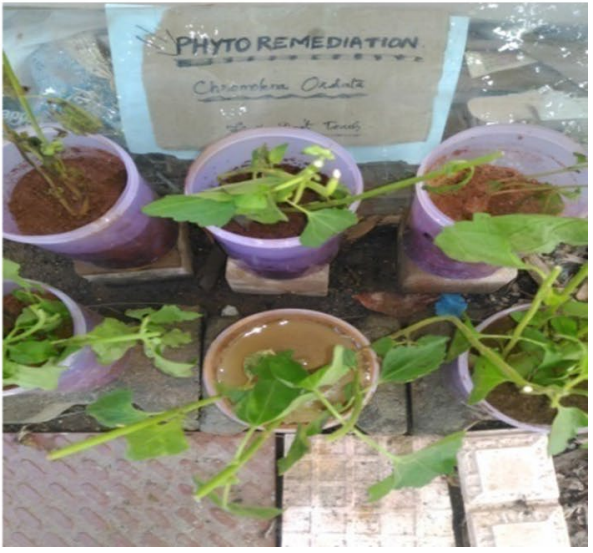

Table 1 Procedure adopted for analyzing soil physical and chemical properties

\begin{tabular}{llll}
\hline Physical parameters & Reference & Chemical parameters & References \\
\hline Moisture content & Oven dry method, IS 2720 Part-II Section-I & $\mathrm{pH}$ & $\mathrm{pH}$ meter \\
Specific gravity & Pycnometer method, IS 2720 Part-III & EC $(\mu \mathrm{s} / \mathrm{cm})$ & Electronic method \\
Atterberg limits & Casagrande apparatus, IS 2720 Part-V & Total organic carbon (\%) & Walkley and Black method (1934) \\
Sieve analysis & Indian Standard Sieve analysis, IS 2720 Part-IV & Total Nitrogen (\%) & Kjeldahl method \\
Optimum moisture content & Standard proctor test, IS 2720 Part-VIII & Available phosphorous (\%) & Bhargava and Raghupati (1993) \\
Maximum dry density & Standard proctor test, IS 2720 Part-VIII & Mineral salt composition & Flame photometry \\
TPH analysis & & $(\mathrm{Ca}, \mathrm{Mg}$, Na and K) & US EPA method 1664 \\
\hline
\end{tabular}

\section{Soil suction measurements-filter paper test}

For the soil suction studies in the laboratory, the filter paper test was performed (Fredlund and Rahardjo 1993). In the site, the ground is cleaned and the top layer of the soil, i.e., approximately $40 \mathrm{~cm}$ from the ground level is dug and removed. Now, the mold is placed and forced into the ground with the use of rammer rod. After the mold is completely penetrated into the soil, using a chisel, the surroundings of the mold are dug and removed slowly in order to make sure that the soil inside the mold is undisturbed. Hydraulic extractors are used to extract the specimen. It is made to cut such that the two pieces are having smooth surfaces on any one side, such that proper placement and intimate contact of the filter paper are maintained.

Plastic jars of height $30 \mathrm{~cm}$ and diameter $10 \mathrm{~cm}$ are used, as they can easily carry the soil specimen which is used in the work. The suction was measured as total suction and matric suction using the standard calibration curves. The relation between the soil suction and the moisture content is calculated using the relationship (Oliveira and Marinho 2006).

The equations proposed by them were

If $w<33 \%, \log _{10}$ (suction) in kpa $=4.83-0.0839 w$

If $w<33 \%, \log _{10}$ (suction) in kpa $=2.57-0.0154 w$ where $w$-water content of the filter paper.

\section{Pumping test}

The pumping tests are carried out in the three wells selected near to the soil sample collection points. The transmissivity is calculated from the pumping test data by a well-known method (Theis 1935).

\section{$K-\theta$ relationship}

As the water content declines and pores become filled with air, the pressure head becomes more and more negative and the hydraulic conductivity decreases. Therefore, relative hydraulic conductivity of unsaturated medium is defined as

$K_{\mathrm{r}}=K / K_{\text {sat }}$

where $K_{\mathrm{r}}$ is the relative hydraulic conductivity, which varies between 0 and $1, K_{\text {sat }}$ is the saturated hydraulic conductivity and $K$ is the unsaturated hydraulic conductivity. The product $K_{\mathrm{r}} K_{\text {sat }}$ shows how the unsaturated hydraulic conductivity is really some fraction of the saturated hydraulic conductivity. In the present study, mentioned relationships were used to calculate the hydraulic conductivity. 
Van Genutchen (1980) relationship

$\mathrm{Se}=\left[\frac{1}{1+(\alpha|\psi|)^{n}}\right]^{m}$

where $\alpha$ is the coefficient, $n$ is the exponent and $m=1-\frac{1}{n}$.

$K_{\mathrm{r}}=\mathrm{Se}^{1 / 2}\left[1-\left(1-\mathrm{Se}^{1 / m}\right)^{m}\right]^{2}$

\section{Fourier transform infrared spectroscopy (FTIR) analysis}

FTIR was performed to identify the functional groups of hydrocarbons present in the natural sample, and 5\% and 10\% crude oil-contaminated samples of each corresponding to site- 1 and site- 2 , before and after the remediation period.

\section{Plant analysis}

Plant parameters were found out to analyze the effect of the plant on remediation study. Parameters such as length of root, number of leaves, the color of leaves, length and girth of roots were recorded at the time of transplanting and after uprooting the test weeds.

\section{Results and discussion}

\section{Soil physical characterization results}

Initial soil characterization for uncontaminated and contaminated soil samples was carried out by adopting standard procedures as explained in "Soil physical and chemical characterization" section.

The grain size distribution of sampling sites was presented in Table 2. The soil collected from site-1 was

Table 2 Soil particle size distribution

\begin{tabular}{lllll}
\hline Sampling site & Gravel (\%) & Sand (\%) & Silt (\%) & Clay (\%) \\
\hline Site-1 & 29.5 & 41.4 & 28.3 & 0.73 \\
Site-2 & 10 & 48.4 & 40.3 & 1.2 \\
\hline
\end{tabular}

observed with sand as $41 \%$ and silt as $28 \%$, respectively, and soil collected from site- 2 was found to possess sand (49\%) and silt (40\%). It was clear that site-2 contains more fines compared to site-1. Other soil physical parameters of the collected soil samples were performed and are shown in Table 3.

The soil moisture content depends on the climatic conditions and a perfect equation cannot be established as it varies from season to season. The soil mixed with crude oil samples shows a decrease in the moisture content proportionally with the contamination concentration. This may be due to the polar and nonpolar reaction of the soil; crude oil is a nonpolar liquid which will adsorb the moisture in the soil and decrease the amount of moisture content in the soil.

The contaminated sample has a significant effect on the liquid limit and plastic limit of the soil. The addition of crude oil to the soil caused the microstructural transformation of the soil. It may be due to the formation of lumps which could glue together with soil particles so as to reduce the influence of water particles. This could be attributed to the increase in the liquid and plastic limits (Khamehchiyan et al. 2007).

\section{Soil chemical characterization results}

Soil chemical analysis was carried to identify the degree of contamination in contaminated and uncontaminated samples. Initial and final deviation of parameters among various percentages of site- 1 and site- 2 are depicted in Table 4 .

The crude oil contamination in the soil shows a significant decrease in the $\mathrm{pH}$ range which implies that due to an increase in the crude oil concentration; the soil tends to become acidic. This acidic nature of the soil is due to the presence of the hydrocarbons in the crude oil which may react with the soil salts and minerals and change the alkaline minerals to acidic. However, there is no much decrease in the $\mathrm{pH}$ of site- 2 and it stays as alkaline even with a $10 \%$ concentration of crude oil. So, it is difficult to analyze the $\mathrm{pH}$ effect for the soil, as it may differ from the type of soil also.

Soil electrical conductivity is the measure that correlates with soil properties that affect crop productivity, including soil texture, cation exchange capacity, drainage conditions, organic content, salinity and subsoil
Table 3 Soil physical characterization

\begin{tabular}{llllllll}
\hline Parameter & \multicolumn{2}{l}{ Site-1 sample } & & \multicolumn{3}{l}{ Site-2 sample } \\
\cline { 2 - 3 } \cline { 7 - 8 } & $0 \%$ & $5 \%$ & $10 \%$ & & $0 \%$ & $5 \%$ & $10 \%$ \\
\hline Moisture content & 9.0 & 11.0 & 11.3 & 7.6 & 7.8 & 8.3 \\
Specific gravity & 2.6 & 2.56 & 2.52 & 2.5 & 2.48 & 2.43 \\
Liquid limit & 32 & 37.0 & 44.5 & 39 & 43.1 & 46.1 \\
Plastic limit & 23 & 27.2 & 33.8 & & 24 & 25.8 & 28.5 \\
Plasticity Index & 8.8 & 10.1 & 10.7 & & 15.3 & 17.4 & 17.6 \\
\hline
\end{tabular}


Table 4 Soil chemical characterization

\begin{tabular}{|c|c|c|c|c|c|c|}
\hline \multirow[t]{2}{*}{ Parameter } & \multicolumn{3}{|c|}{ Site-1 sample } & \multicolumn{3}{|c|}{ Site-2 sample } \\
\hline & $0 \%$ & $5 \%$ & $10 \%$ & $0 \%$ & $5 \%$ & $10 \%$ \\
\hline $\mathrm{pH}$ & 6.95 & 6.74 & 6.54 & 7.68 & 7.36 & 7.02 \\
\hline Conductivity $(\mu \mathrm{S} / \mathrm{Cm})$ & 107.2 & 119.7 & 133.4 & 56.4 & 71.3 & 96.8 \\
\hline Moisture (\%) & 10.5 & 11.01 & 11.26 & 7.59 & 7.80 & 8.31 \\
\hline Soil organic carbon (\%) & 0.45 & 1.82 & 3.97 & 2.76 & 4.85 & 11.44 \\
\hline Total nitrogen $(\%)$ & 0.15 & 0.08 & 0.03 & 0.49 & 0.22 & 0.13 \\
\hline Available phosphorous (\%) & 8.7 & 6.5 & 5.8 & 4.8 & 3.4 & 2.6 \\
\hline Potassium (\%) & 0.83 & Traces & Traces & 0.51 & Traces & Traces \\
\hline
\end{tabular}

characteristics. As crude oil consists of petroleum hydrocarbons, possess huge count of ions could bond with the existing ions in the soil. Thus, the electrical conductivity of the contaminated soil gets increased due to the increase in the contamination.

Organic carbon in the soil is generally accounted for the peat formation and microbial biomass. The results obtained during the tests of organic carbon display that the total organic carbon concentration will increase due to an increase in crude oil contamination. This is due to the presence of petroleum hydrocarbons in the crude oil which may result in agronomical addition of the carbon content to the soil.

Organic matter will influence the plant growth based on the nutrient availability directly or indirectly. So if the organic carbon in the soil increases due to the contamination, it requires more microorganisms to supply nutrients which results in the decrease in total nitrogen and available phosphorus concentrations of the soil. It indicates soil is porous in nature. The carbon-hydrogen mixture of petroleum hydrocarbon causes spill on the soil to upset the carbon-nitrogen balance. Therefore, the effective metabolism, growth and development of living organisms in the soil, a relatively high carbon-nitrogen ration and a carbon-phosphorous ratio are ideal. Carbon and nitrogen values have decreased to a minimum level due to carbon mineralization and hydrocarbon immobilization resulting in excessive microbial activity using carbon materials as an energy source and its attendant demand for more nitrogen. So the organic carbon in the soil reacts in the form of nitrogen as ammonium $\left(\mathrm{NH}^{4+}\right)$ or nitrate $\left(\mathrm{NO}^{3-}\right)$ ions and gets evaporated, due to which the nitrogen content in the contaminated soil is decreased with an increase in crude oil contamination.
The available phosphorus concentration decreases due to the increase in contamination. This decrease in available phosphorus may be caused due to two reasons. Firstly, the petroleum hydrocarbons in crude oil could increase the carbon concentration to the soil, which might affect the nutrients equilibrium in the soil. Secondly, microbes in the soil may utilize considerable amounts of available phosphorus to degrade the hydrocarbons present in the soil.

\section{TPH analysis of soil}

The results of initial and final TPH analysis of both uncontaminated and contaminated site- 1 and site- 2 samples and removal efficiency of hydrocarbons by Chromolaena odorata were presented in Table 5. Functional groups present in each soil sample were identified before and after the treatment (Ayotamuno et al. 2006) by FTIR studies. TPH of $52.9 \%$ and $53.6 \%$ and $45.98 \%$ and $57.72 \%$ removal was observed in 5\% and $10 \%$ oil-contaminated site- 1 and site- 2 soils within 7 weeks of remediation period.

\section{Soil suction measurements}

The soil suction is estimated by calculating the obtained moisture content from the filter paper test. The values of both matric and total suction were portrayed in Figs. 2 and 3 , respectively.

\section{Soil water characteristics}

From the filter paper tests, the gravimetric moisture content of the soil specimens was found and using which, the unsaturated hydraulic conductivity was determined and presented
Table 5 TPH analysis of soil samples

\begin{tabular}{|c|c|c|c|c|c|c|}
\hline \multirow[t]{2}{*}{ Crude oil } & \multicolumn{2}{|c|}{ Initial TPH (mg/g) } & \multicolumn{2}{|c|}{ Final TPH (mg/g) } & \multicolumn{2}{|c|}{ Removal efficiency } \\
\hline & Site-1 & Site-2 & Site-1 & Site-2 & Site-1 & Site-2 \\
\hline $0 \%$ & 0 & 0 & - & - & - & - \\
\hline $5 \%$ & 10 & 10 & 6.5 & 6.5 & $52.9 \%$ & $53.6 \%$ \\
\hline $10 \%$ & 20 & 20 & 13.7 & 12.7 & $45.9 \%$ & $57.7 \%$ \\
\hline
\end{tabular}




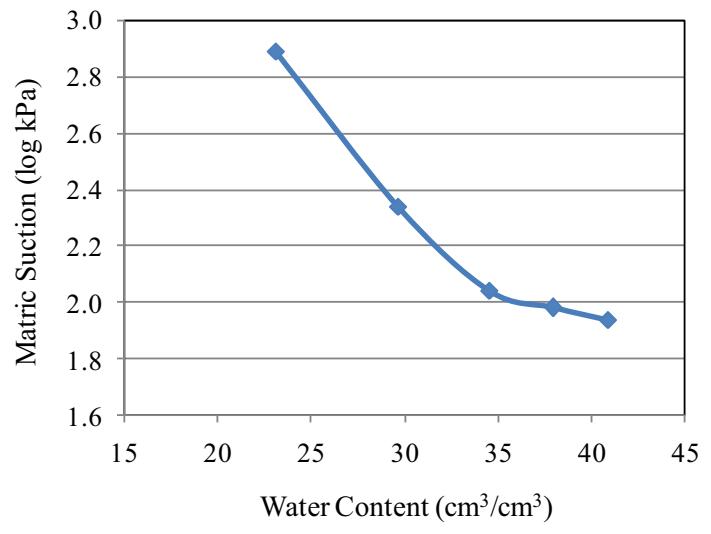

Fig. 2 Moisture content versus matric suction

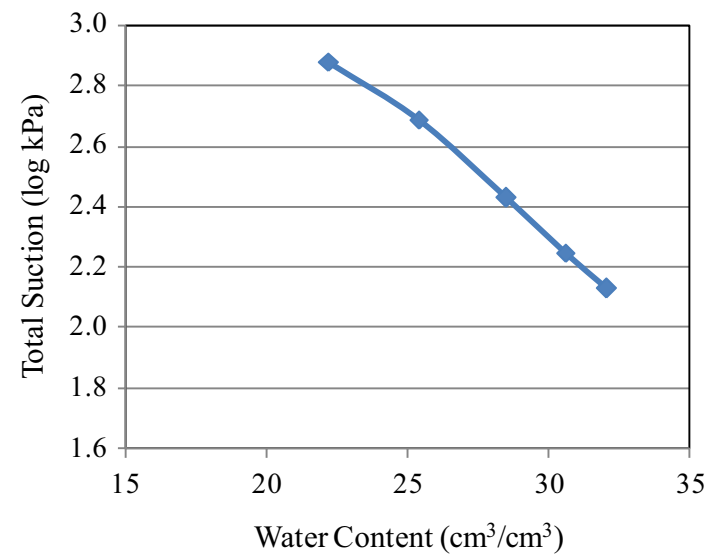

Fig. 3 Moisture content versus total suction

Table 6 Estimation of unsaturated hydraulic conductivity

\begin{tabular}{llll}
\hline Sampling site & $\begin{array}{l}\text { Suction } \\
(\log \mathrm{kPa})\end{array}$ & $\begin{array}{l}\text { Moisture } \\
\text { content } \theta\left(\mathrm{cm}^{3} /\right. \\
\left.\mathrm{cm}^{3}\right)\end{array}$ & $\begin{array}{l}\text { Hydraulic } \\
\text { conductivity } K \\
(\mathrm{~m} / \mathrm{s})\end{array}$ \\
\hline Site-1 & 2.69 & 0.25 & $6.54 \times 10^{-5}$ \\
& 2.43 & 0.28 & $11.4 \times 10^{-5}$ \\
Site-2 & 1.89 & 0.35 & $10.389 \times 10^{-5}$ \\
Site-2 (contaminated) & 3.11 & 0.22 & $5.189 \times 10^{-5}$ \\
\hline
\end{tabular}

in Table 6 by Van Genuchten relationships. For site- $1, \theta_{\mathrm{r}}$ is $0.061, \theta_{\mathrm{s}}$ is $0.43, \alpha$ is $0.012, n$ is 1.39 , and for site $-2, \theta_{\mathrm{r}}$ is $0.123, \theta_{\mathrm{s}}$ is $0.48, \alpha$ is $0.006, n$ is 1.53 .

\section{Well pumping tests}

The pumping tests are carried out in the wells selected near to the soil sample collection points. The average saturation thickness range (10 m) was adopted (Mahesha et al. 2012).
The saturated hydraulic conductivity is calculated from pumping test data. Aquifer parameters like transmissivity $(T)$ and $K$ for site- 1 were $115.2 \mathrm{~m}^{2} /$ day and $11.52 \mathrm{~m} /$ day, and for site-2, $207.36 \mathrm{~m}^{2} /$ day and $20.7 \mathrm{~m} /$ day, respectively.

The relative hydraulic conductivity $\left(K_{\mathrm{r}}\right)$ is calculated and was observed that for site- $1, K_{\mathrm{r}}$ varies by $31 \%$ with respect to saturated hydraulic conductivity. The obtained results are evident that soil is having higher moisture content and porosity which directly relates to increased hydraulic conductivity. Experiments were conducted for estimating saturated and unsaturated hydraulic conductivity for the uncontaminated and contaminated samples ( $6 \%$ of crude oil by dry weight of soil) for site-2. It is observed that for uncontaminated soil sample, $K_{\mathrm{r}}$ varies by $46 \%$ with respect to saturated hydraulic conductivity and for the contaminated sample, it varies by $57 \%$. It was inferred that more than $50 \%$ of water flow is contributed by unsaturated hydraulic conductivity in case of contaminated soil. Due to the oil coating which surrounds the soil particles, it reduces the availability of water to the plant roots because of the gradient development between the soil particles and pore spaces. Sometimes, pore space may be trapped by oil content instead of water particles. As a result, the moisture flow from soil to root is reduced and sometimes a reverse flow occurs, due to which conductivity of soil is reduced. The reported results were in agreement (Devatha et al. 2016). Hence, it clearly shows that crude oil contamination reduces the pore size of the soil which in turn hydraulic conductivity.

\section{FTIR results}

FTIR results were used to identify the functional groups of hydrocarbons present in 5\% and 10\% crude oil-contaminated samples of each corresponding site- 1 and site- 2 soil before and after the remediation period. Functional groups present in the soil samples were obtained through FTIR and are shown in Fig. 4a-d for site-1 and from Fig. 5a-d for site-2.

It was recognized that in 5\% and $10 \%$ crude oil-contaminated site- 1 soil, before remediation, FTIR spectra had indicated several functional groups present in the sample. FTIR spectra indicated $(\mathrm{O}-\mathrm{H})$ group ranging from 3618.43 to $3734.98 \mathrm{~cm}^{-1}$ and 3618.94 to $3691.21 \mathrm{~cm}^{-1}$ wave number, (C-H) group from 2853.72 to $2922.92 \mathrm{~cm}^{-1}$ and 2851.90 to $2952.77 \mathrm{~cm}^{-1}$ ( $\mathrm{Si}-\mathrm{H}$ ) compounds from 2341.07 to $2360.74 \mathrm{~cm}^{-1}$ range, $(\mathrm{C}=\mathrm{C})$ group compounds in the wave number ranging in $1456.96 \mathrm{~cm}^{-1}$ and $1457.87 \mathrm{~cm}^{-1},(\mathrm{C}-\mathrm{O})$ compounds in a range of $1091.55 \mathrm{~cm}^{-1}$ and $1375.96 \mathrm{~cm}^{-1}$, (-O-C) compounds from 1000.68 to $1027.62 \mathrm{~cm}^{-1}$ range, while $(\mathrm{C}-\mathrm{C})$ compounds are in $908.00 \mathrm{~cm}^{-1}$ wave number, and $(\mathrm{NH} 2, \mathrm{~N}-\mathrm{H}$ and $\mathrm{C}-\mathrm{H})$ compounds are in between a wave number ranging from 668.27 to $682.49 \mathrm{~cm}^{-1}$. The $\mathrm{C}-\mathrm{H}$ and $\mathrm{O}-\mathrm{H}$ bonds present to confirm that the alkanes group of hydrocarbons are present in it. 

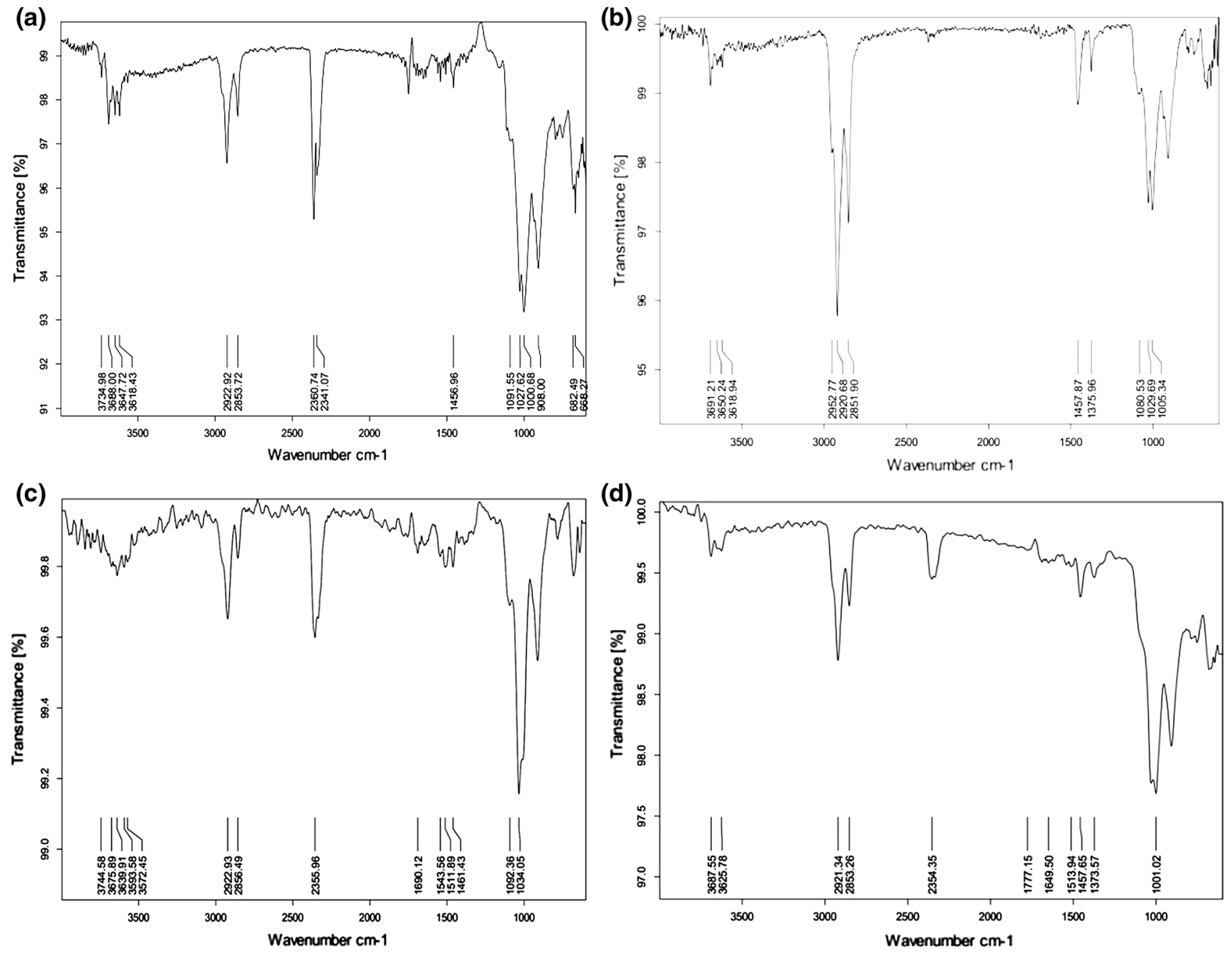

Fig. 4 a Initial 5\% contaminated site-1 sample, b initial 10\% contaminated site-1 sample, c final 5\% contaminated site-1 sample, d final 10\% contaminated site- 1 sample

After remediation, it was found to indicate various functional groups present in the sample. The spectra indicated $(\mathrm{O}-\mathrm{H})$ group ranging from 3572.45 to $3744.58 \mathrm{~cm}^{-1}$ wave number and 3625.78 to $3687.55 \mathrm{~cm}^{-1}$, (C-H) group from 2856.49 to $2922.93 \mathrm{~cm}^{-1}$ and 2853.26 to $2921.34 \mathrm{~cm}^{-1},(\mathrm{C}=\mathrm{C})$ group compounds in the wave number ranging between 1461.43 and $1543.56 \mathrm{~cm}^{-1}$ and 1457.65 to 1649.50 , while $(\mathrm{C}=\mathrm{O})$ compounds in a range of $1690.12 \mathrm{~cm}^{-1}$ and $1777.15 \mathrm{~cm}^{-1}$ range, $(\mathrm{C}-\mathrm{C})$ compounds in $1034.05-1092.36 \mathrm{~cm}^{-1}$ and $1001.02 \mathrm{~cm}^{-1}$ range and $(\mathrm{P}-\mathrm{H})$ compounds in $2355.96 \mathrm{~cm}^{-1}$ range and $2354.35 \mathrm{~cm}^{-1}$.

FTIR spectra had shown the presence of various functional groups present in site- 2 sample for $5 \%$ and $10 \%$ before remediation. FTIR spectra indicated $(\mathrm{O}-\mathrm{H})$ group ranging from wave numbers, $2853.94-2922.07 \mathrm{~cm}^{-1}$ and $2853.28-2922.74 \mathrm{~cm}^{-1}$ (S-H) compounds from 2341.50 to $2361.19 \mathrm{~cm}^{-1}$ and 2342.05 to $2363.25 \mathrm{~cm}^{-1}$, (P-OR) compounds from 908.52 and $1085.43 \mathrm{~cm}^{-1}$ range, while (Alkyl bromide) compounds are in between a wave number ranging from 668.56 to $667.00 \mathrm{~cm}^{-1}$.

After remediation, the spectra indicated $(\mathrm{O}-\mathrm{H})$ group ranging from 3401.03 to $3747.16 \mathrm{~cm}^{-1}$ and 3452.81 to $3687.47 \mathrm{~cm}^{-1}$ wave number, $(\mathrm{C}=\mathrm{C}=\mathrm{O})$ group from 2359.83 to $2591.89 \mathrm{~cm}^{-1},(\mathrm{C}=\mathrm{O})$ compounds from 1766.01 to $1964.32 \mathrm{~cm}^{-1}$ range, $(\mathrm{C}=\mathrm{C})$ group compounds in the wave number ranging in $1506.77-1643.88 \mathrm{~cm}^{-1},(-\mathrm{O}-\mathrm{C}) \mathrm{com}-$ pounds from 1000.68 to $1027.62 \mathrm{~cm}^{-1}$ range, while $(\mathrm{C}-\mathrm{C})$ compounds are in $2041.23-2148.18 \mathrm{~cm}^{-1}$ and $1031.57 \mathrm{~cm}^{-1}$ and also in $1033.42 \mathrm{~cm}^{-1}$ wave number, and $(\mathrm{N}=\mathrm{O}) \mathrm{com}-$ pounds in a wave number ranging at $1390.94 \mathrm{~cm}^{-1},(\mathrm{C}-\mathrm{H})$ group from 2853.10 to $2916.26 \mathrm{~cm}^{-1}$.

It was obvious that the different functional groups are responsible for petroleum hydrocarbons present in soil samples. It was seen that respective functional groups such as alcohols, phenols, methyl group, aliphatic hydrocarbons, amide group are accountable for the presence of petroleum 
(a)

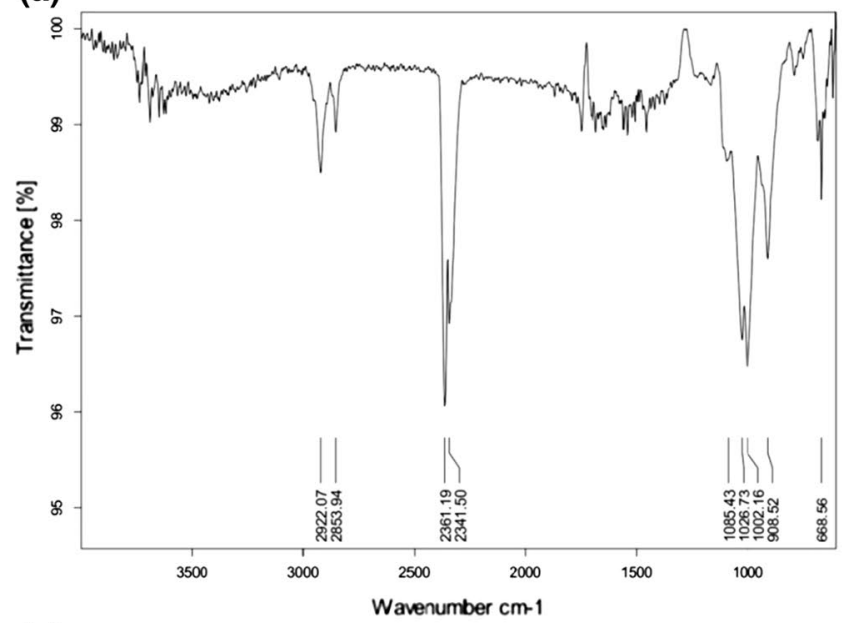

(c)

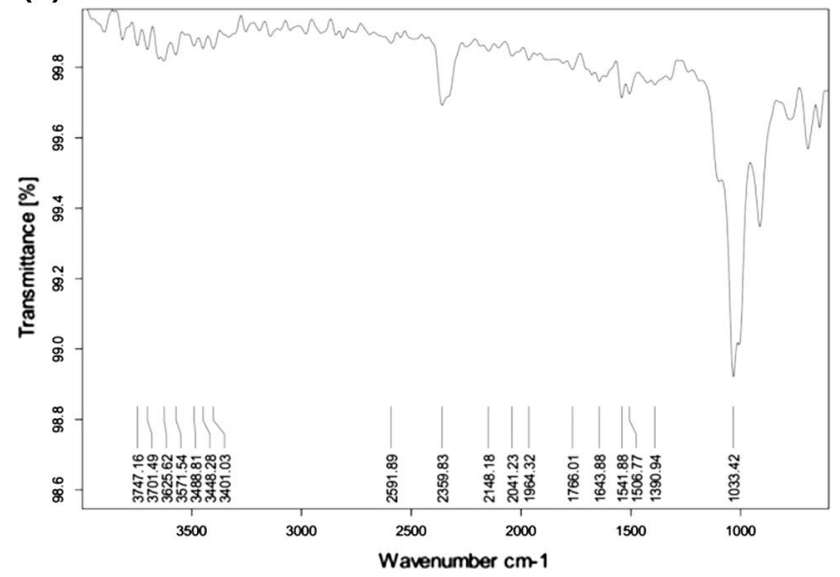

(b)

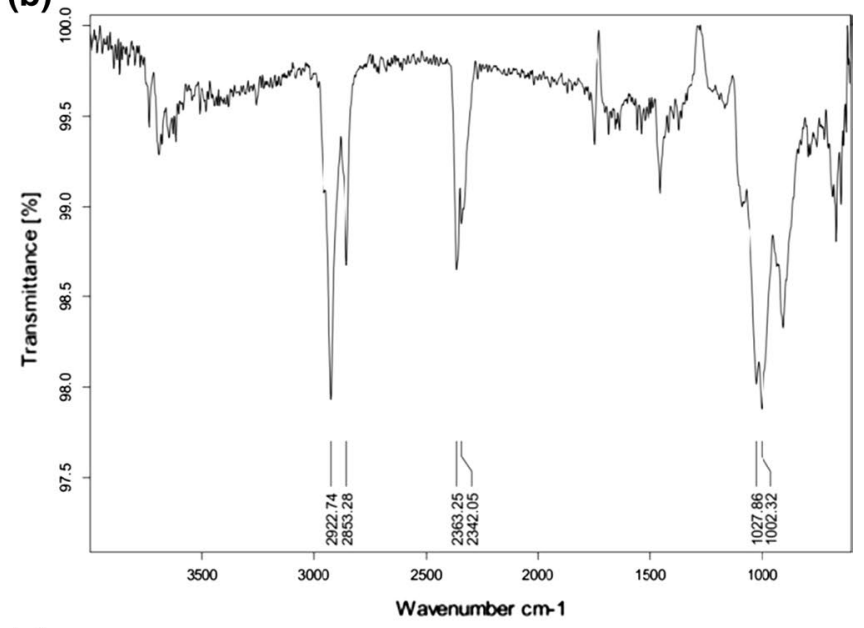

(d)

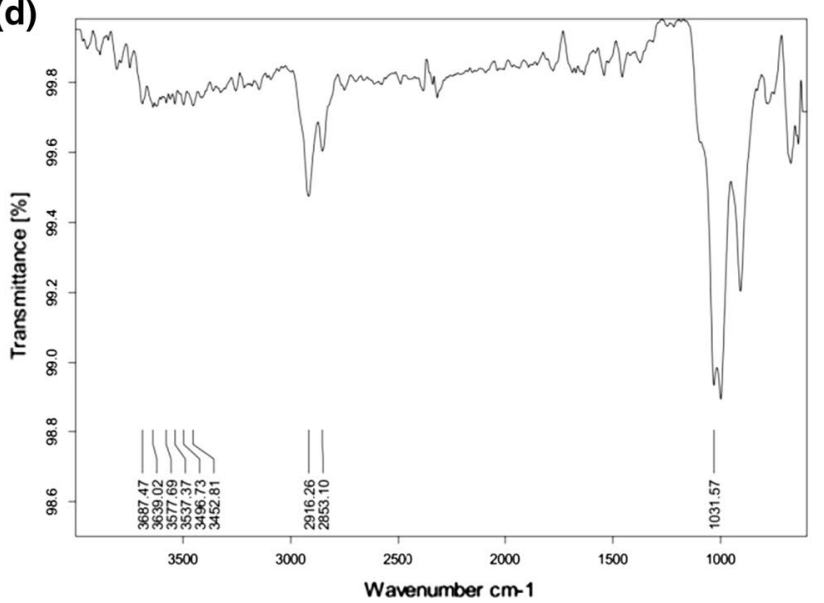

Fig. 5 a Initial 5\% contaminated site-2 sample, b initial 10\% contaminated site-2 sample, c final 5\% contaminated site-2 sample, d final 10\% contaminated site-2 sample

hydrocarbons and the same characteristic peaks have been observed but at lower intensity when there was an increase in the concentration of oil content. It can be attributed like the adopted plant species can degrade oil contamination and it is evident through the FTIR results after 7 weeks of the plantation.

\section{Plant parameters}

Plant analysis through general observations before and after the remediation period was done for site- 1 and site- 2 soil sample with $0 \%$ and 5\% crude oil contamination. Recorded parameters are shown in Table 7 and growth was depicted from Fig. 6.

Due to the presence of available moisture in the soil, favorable conditions were raised and therefore they used the nutrients present in the soil and shown normal growth of leaves and shoots of the plants grown in site- 1 and site- 2 soil samples. It is observed from the study that site- 2 soil samples showed better growth in terms of roots and shoots (increased number of leaves and color of leaves in green color) compared to site- 1 and it is shown in Fig. 6.

Overall, due to crude oil contamination, soil moisture was reduced with an increase in oil contamination which could have occurred due to the hydrophobic coating of oil around the soil particles causing a reduction in soil hydraulic conductivity, and the same trend have been obtained with specific gravity also. This acidic nature of the soil is due to the presence of the hydrocarbons in the crude oil which may react with the soil salts and minerals and change the alkaline minerals to acidic. However, there is no much decrease in the $\mathrm{pH}$ of the site- 2 sample and it stays as an alkaline condition even with a $10 \%$ concentration of crude oil. Hence, in this study, $\mathrm{pH}$ is not causing any significant change nevertheless it may differ based on soil type. Available phosphorus presented the declining trend with augmenting oil contamination (Wang et al. 2009). Available phosphorus is an essential macronutrient for plant and soil microorganisms; the 
Table 7 Plant parameters of soil during transplantation and after

\begin{tabular}{|c|c|c|c|c|c|c|c|c|}
\hline \multirow[t]{3}{*}{ Parameter } & \multicolumn{4}{|c|}{ Site-1 sample } & \multicolumn{4}{|c|}{ Site-2 sample } \\
\hline & \multicolumn{2}{|c|}{$\begin{array}{l}\text { During transplant- } \\
\text { ing }\end{array}$} & \multicolumn{2}{|c|}{ After harvest } & \multicolumn{2}{|c|}{$\begin{array}{l}\text { During transplant- } \\
\text { ing }\end{array}$} & \multicolumn{2}{|c|}{ After harvest } \\
\hline & $5 \%$ & $10 \%$ & $5 \%$ & $10 \%$ & $5 \%$ & $10 \%$ & $5 \%$ & $10 \%$ \\
\hline Length of shoot & $8.66^{\prime \prime}$ & $7.48^{\prime \prime}$ & $9.5^{\prime \prime}$ & 8.74" & $12.6^{\prime \prime}$ & $8.66^{\prime \prime}$ & $13.1^{\prime \prime}$ & $9.8^{\prime \prime}$ \\
\hline Length of root & $7.48^{\prime \prime}$ & $9.12^{\prime \prime}$ & 7.52" & $9.30^{\prime \prime}$ & 7.87" & $6.59^{\prime \prime}$ & $8.54 "$ & $6.73^{\prime \prime}$ \\
\hline Number of leaves & 17 & 26 & 38 & 49 & 15 & 35 & 39 & 86 \\
\hline
\end{tabular}

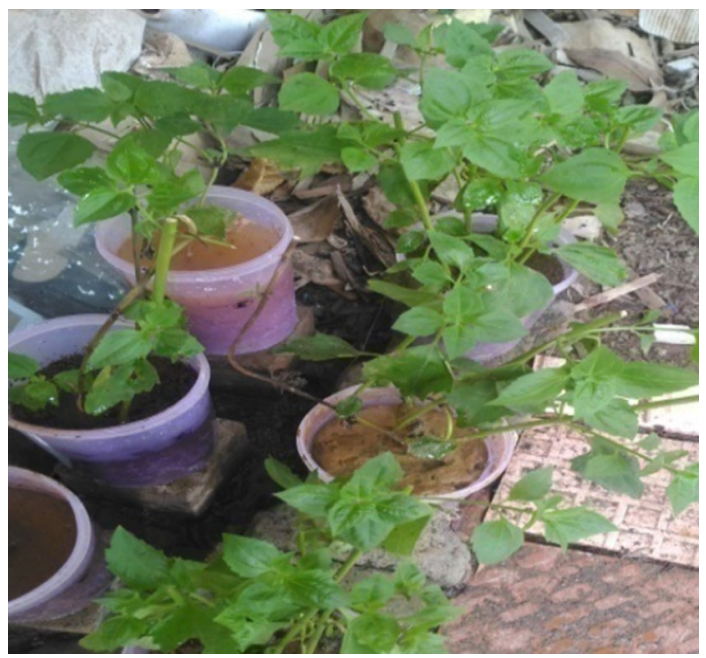

Fig. 6 Growth of plants with oil contamination

reduction could have attributed to the imbalance in the availability of nutrients due to the increase in carbon concentration. TOC concentration had increased due to an increase in TPH as reported by similar other studies (Wang et al. 2009).

Relative hydraulic conductivity of contaminated and uncontaminated sample was obtained to critically evaluate the effects on soil. In the present study, it obtained as 0.46 and 0.57 , respectively. Analogous to this, the variation of unsaturated hydraulic conductivity demonstrates the significant effects on soil moisture characteristics due to salinity (Devatha et al. 2016). The results obtained are alike to the findings (Chew and Lee 2006).

This study attempted hydraulic conductivity variation in field soil samples to arrive at appropriate $K_{\mathrm{r}}$. This parameter plays a key role in water movement in the soil to roots. The results showed that the conductivity of contaminated soil was affected by $10 \%$ and could reduce the pore size. Phytoremediation as a cleanup tool using Chromolaena odorata had performed satisfactorily for 5\% and $10 \%$ oil contamination as it is evident that aromatic hydrocarbon concentration was reduced in soil samples more in 5\% and comparatively less in $10 \%$. Site- 1 soil showed better removal of hydrocarbons in 5\% compared to $10 \%$ oil-contaminated soil. In the case of site- 2 soil, removal of hydrocarbons is more in $10 \%$ contaminated soil than in $5 \%$ which may be due to the soil type. Site- 2 soil sample consists of more fines which are available to adsorb cation stands responsible for the higher inherent fertility of the soil. Because of the available moisture present in the soil, enough nutrients were derived for proper growth of leaves and shoots compared to those grown in site- 1 soil. Further enhancement might be carried out for a longer time period to effectively study the variation in soil and plant behavior.

High (10\%) oil content led to lowering of moisture content in the soil which obstructs sufficient water availability, reduction in available phosphorus and increase in TPH for normal plant growth compared to less oil content (5\%) in the investigated time period. Hence, it is understandable that removal of oil contamination happens to diverge with the level of contamination and also in restoring the soil hydraulic conductivity.

\section{Conclusion}

In the present study, the effect of crude oil contamination in soil was studied on its physical and chemical properties and revealed that it is harmful to the soil environment. The experimental investigation demonstrated that soil properties like moisture content, available phosphorus and TOC have significant effects due to oil contamination. Hydraulic conductivity is a high-impacting parameter and was studied experimentally to estimate unsaturated and saturated hydraulic conductivity in both sites. $K_{\mathrm{r}}$ was obtained as 0.46 and 0.57 for uncontaminated and contaminated samples. It reveals that oil contamination was reducing the conductivity of soil by $10 \%$. Remediation by Chromolaena odorata found to be effective in site-1 (53\% and 46\%) and site- 2 soil ( $54 \%$ and $58 \%$ ) for removal of petroleum hydrocarbons after 7 weeks. In the site- 1 sample, the weed showed higher removal efficiency in 5\% oil contamination soil than in $10 \%$, whereas in the site- 2 sample, it was vice versa due to soil type. 
Open Access This article is distributed under the terms of the Creative Commons Attribution 4.0 International License (http://creativeco mmons.org/licenses/by/4.0/), which permits unrestricted use, distribution, and reproduction in any medium, provided you give appropriate credit to the original author(s) and the source, provide a link to the Creative Commons license, and indicate if changes were made.

\section{References}

Akubugwo EI, Chinyere GC, Ogbuji GC, Ugbuagu EA (2009) Physiochemical property of enzyme activity in a refined oil contaminated soil in Isuikwuato L.G.A., Abia State. Niger Soc Environ Biol 2:79-84

Akunwumi II, Diwa D, Obianigwe N (2014) Effects of crude oil contamination on the index properties, strength and permeability of lateritic clay. Int J Appl Sci Eng Res 3:816-824

Al-Khafaf S, Hanks RJ (1974) Evaluation of the filter paper method for estimating soil water potential. Soil Sci 117:194-199

Al-Sanad HA, Eid Walid K, Ismael NF (1995) Geotechnical properties of oil contaminated Kuwaiti sand. J Geotech Eng ASCE 121:407-412

Ayotamuno J, Kogbara RB, Ogaji S, Proberst SD (2006) Bioremediation of a crude-oil polluted agricultural-soil at Port Harcourt, Nigeria. Appl Energy 83:1249-1257

Bhargava BS, Raghupati HB (1993) Analysis of plant materials for macro and micronutrients. In: Tandon HLS (ed) Methods of analysis of soil, plants, water and fertilizers. FDCO, New Delhi, pp 49-82

Chew S, Lee C (2006) Simple shear behaviour of palm biodiesel contaminated soil. J Eng Appl Sci 5:1-12

Devatha CP, Shankar V, Ojha CSP (2016) Assessment of soil moisture uptake under different salinity levels for paddy crop. J Irrig Drain Eng 142:04016011

Ekundayo E, Obuekwe O (2000) Effects of an oil spill on soil physicochemical properties of a spill site in a typic udipsamment of the Niger delta basin of Nigeria. Environ Monit Assess 60:235-249

Fredlund DG, Rahardjo H (1993) Soil mechanics for unsaturated soils. Wiley, New York

Hamblin AP (1981) Filter paper method for routine measurement of field water potential. J Hydrol 53:355-360

Jagtap SS, Woo SM, Kim T, Dhiman SS, Kim D, Lee J (2014) Phytoremediation of diesel-contaminated soil and saccharification of the resulting biomass. Fuel 116:292-298

Kathi S, Khan AB (2011) Phytoremediation approaches to PAH contaminated soil. Indian J Sci Technol 4:56-63

Khamehchiyan M, Charkhabi AM, Tajik M (2007) Effects of crude oil contamination on geotechnical properties of clayey and sandy soils. Eng Geol 89:220-229
Kogbara RB (2007) The effects of different levels of nutrients on the degradation of petroleum polluted agricultural soil. A dissertation, University of Science Technology, Rivers State, Nigeria, pp 34-42

Mahesha A, Vyshali Lathashri U A, Ramesh H (2012) Parameter estimation and vulnerability assessment of coastal unconfined aquifer to saltwater intrusion. J Hydrol Eng 17:933-943

Marinho FAM, Oliveira OM (2006) The filter paper method revised. ASTM Int 29:250-258

Moreira IT, Oliveira OM, Triguis JA, dos Santos AM, Queiroz AF, Martins CM, Silva CS, Jesus RS (2011) Phytoremediation using Rizophora mangle L. in mangrove sediments contaminated by persistent total petroleum hydrocarbons (TPH's). Microchem J 30:376-382

Nazir AK (2011) Effect of motor oil contamination on geotechnical properties of over consolidated clay. Alex Eng J 50:331-335

Oliveira OM, Marinho FAM (2006) Evaluation of filter paper calibration. In: Unsaturated soils, pp 1845-1851

Paz-Alberto AM, Sigua GC (2013) Phytoremediation: a green technology to remove environmental pollutants. Am J Clim Change 2:71-86

Singh S, Thorat V, Kaushik CP, Raj Kanwar, D’Souza SF (2009) Potential of Chromolaena odorata for phytoremediation of 137Cs from solution and low level nuclear waste. J Hazard Mater 162:43-745

Sutton NB, Maphosa F, Morillo JA et al (2013) Impact of long-term diesel contamination on soil microbial community structure. Appl Environ Microbiol 79:619-630

Theis CS (1935) The relation between the lowering of piezometric surface and the data and duration of discharge of a well-using groundwater storage. In: American geophysics union transcripts, 16th annual meeting, part 2, pp 519-524

Van Genutchen MT (1980) A closed-form equation for predicting the hydraulic conductivity of unsaturated soil. Soil Sci Soc Am J 44:892-898

Walkey A, Black IA (1934) Methods of soil analysis. Science 37:29

Wang X, Feng J, Wang J (2009) Petroleum hydrocarbon contamination and impact on soil characteristics from an oilfield in Momoge wetland. Environ Sci 30:2394-2401

Wang XY, Feng J, Zhao JM (2010) Effects of crude oil residuals on soil chemical properties in oil sites, Momoge Wetland, China. Environ Monit Assess 161:271-280

Yalin H, Silong W, Shaokui Y (2006) Research advances on the factors influencing the activity and community structure of soil microorganism. Chin J Soil Sci 37:170-176

Publisher's Note Springer Nature remains neutral with regard to jurisdictional claims in published maps and institutional affiliations. 